\title{
The interrelationship between water access, exclusive breastfeeding and diarrhea in children: a cross-sectional assessment across 19 African countries
}

\author{
Paschal A Apanga ${ }^{1}$, \\ Ann M Weber ${ }^{1}$, \\ Lyndsey A Darrow ${ }^{1}$, \\ Mark S Riddle? \\ Wei-Chen Tung ${ }^{3}$, \\ Yan Liu ${ }^{1}$, Joshua V Garn ${ }^{1}$ \\ ${ }^{1}$ School of Community Health \\ Sciences, University of \\ Nevada, Reno, Nevada, USA \\ ${ }^{2}$ School of Medicine, \\ University of Nevada, Reno, \\ Nevada, USA \\ ${ }^{3}$ The Valley Foundation of \\ School of Nursing, San Jose \\ State University, San Jose, \\ California, USA
}

\begin{abstract}
Background Access to an improved water supply and practicing exclusive breastfeeding are essential for improving maternal and child health outcomes. However, few studies have been equipped to assess the interdependencies between access to improved water, practicing exclusive breastfeeding, and child health. The primary aim of our study was to assess whether access to an improved water supply and water-fetching were associated with mothers' practice of exclusive breastfeeding.
\end{abstract}

Methods We analyzed data on 247090 mothers with children 5 months old or less using Multiple Indicator Cluster Surveys from 19 African countries. Multivariable logistic regression was used to estimate the relationship between our exposures and exclusive breastfeeding practice, while meta-analytic methods were used to pool adjusted estimates across 19 countries.

Results The prevalence of exclusive breastfeeding ranged from 22\% in Nigeria to $70 \%$ in Malawi. Pooled results showed water-fetching was not associated with exclusive breastfeeding (adjusted prevalence odds ratios $(\mathrm{aPOR})=1.04$, 95\% confidence inter$\operatorname{val}(\mathrm{CI})=0.89,1.21)$. Access to an improved water source was also not associated with exclusive breastfeeding $(\mathrm{aPOR}=1.06,95 \% \mathrm{CI}=0.94,1.21)$. Across all countries many women were spending a significant amount of time water-fetching each day (mean time varied from 20 minutes in Ghana to 115 minutes in Mauritania). Exclusively breastfed children had 33\% lower odds of diarrhea than those who were not exclusively breastfed $(\mathrm{aPOR}=0.67,95 \% \mathrm{CI}=0.56,0.78)$.

Conclusion Our study is the first to assess the relationship between access to improved water supply, water-fetching and exclusive breastfeeding. We found that access to water supply and time spent by mothers fetching water were not associated with exclusive breastfeeding practice, even though mothers spent significant time fetching water.

Ingestion is a particularly important pathway for acquisition of enteropathogens that cause acute diarrheal illness, which is responsible for $10 \%-12 \%$ of all deaths in children under 5 years of age $[1,2]$. Interventions that provide microbiologically clean water can act as a barrier to pathogen acquisition [3]. Exclusive breastfeeding (EBF) may also act as a barrier, and simultaneously builds children's immunity, protecting them from diarrheal and respiratory diseases and improving their response to vaccination [4-7]. Both access to microbiologically safe water and practicing exclusive breast feeding are important, but few studies have been equipped to assess the interdependencies between these. 
It is not known whether household water-fetching is associated with a woman's practice of EBF or time available to exclusively breastfeed. Women without adequate water spend much of their time and energies water-fetching $[8,9]$, which could compete with time to exclusively breastfeed. There is some evidence exploring the links between water-fetching and other health practices, such as antenatal care attendance, and health facility delivery [10]. There are few studies assessing the effects of water-fetching on diarrhea in children [1012], while most studies focus on the high risk of contamination [13-15]. However, it's not known how time spent water-fetching affects the practice of EBF.

There are a number of perceptions about water source types and water quality that might lead to women introducing water prematurely. It has been reported that many women believe that infants can be given water if the water is clean [16]. Similarly, women who perceive that their own water quality is good are more likely to drink that water compared to women believing that their water quality is poor [17,18]. Further, perceptions of water cleanliness might not align with if the water is actually microbiologically safe. It is widely perceived that piped water is the "ideal" compared to other water sources, although contaminated piped water has been reported in a range of settings [19]. Similarly, women who have access to improved water sources might be better protected from contaminants compared to their counterparts with unimproved water sources, but not all improved water sources are safe or consistently safe $[19,20]$.

Even when an infant is exclusively breastfed, they may be at increased risk of infection if other household members are exposed to microbiologically contaminated water. Lack of safe water, sanitation, and hygiene (WASH) accounts for an estimated 88\% of diarrhea-associated mortality in young children [21,22], and many of these deaths are children who were exclusively breastfed, but living in families with high prevalence of WASH preventable diseases. Children within the first two years of life are most vulnerable, with a decline in mortality as the child grows older [23]. Interventions that provide water supply improvements are therefore essential in reducing diarrheal diseases among young children [24].

This study characterizes the pathways between improved water access, water-fetching, EBF, and diarrhea in children living in 19 African countries, using the Multiple Indicator Cluster Surveys (MICSs) [25]. Our primary aims were to assess the association between access to improved water supply and EBF practice, and between water-fetching and EBF during the first five months after birth. Our secondary aims were to characterize the association between access to an improved water supply and diarrhea prevalence, and between EBF and diarrhea prevalence in children five months old or less.

\section{METHODS}

\section{Study design, setting and data collection}

We used data from the MICS from 19 African countries, collected between 2013 and 2019. The MICS is a nationally representative household cross-sectional study conducted in many countries around the world, with systematically collected data on women and children [25]. Our study population was mothers with children five months old or less living in the following African countries: Democratic Republic of Congo (DRC), Gambia, Ghana, Lesotho, Madagascar, Sierra Leone, Togo, Zimbabwe, Cameroon, Congo, Côte d'Ivoire, Benin, Guinea Bissau, Guinea, Malawi, Mali, Mauritania, Nigeria, and Sudan. Most of the countries (12) were from West Africa, three from East Africa, one from North Africa, one from Southern Africa, and two from Central Africa.

The MICS employs a two-stage sampling technique in each country. In the first stage, census enumeration areas were selected from each sampling strata using probability proportional to size of the number of households in each enumeration area. The second stage of sampling involved selection of households using systematic random sampling from each enumeration area, forming survey clusters. Household participation rates are usually 90\%-95\% [25]. Detailed description of the MICS sampling design and procedures are published elsewhere [26,27].

\section{Outcome measures}

Our primary outcome of interest was exclusive breastfeeding practice. Exclusive breastfeeding was dichotomized as "yes" for infants five months of age or less who were still being breastfed and did not receive other fluids/foods in the past 24 hours, and categorized as "no" for infants five months of age or less who were not being breastfed, or were still being breastfed but received other fluids/foods in the past 24 hours [28]. Our secondary outcome was caregiver-reported diarrhea in the past two weeks. This variable was also dichoto- 
mized as "yes" for infants whose parents had reported diarrhea in the past two weeks and "no" for infants who did not have diarrhea.

\section{Predictors}

The predictors in our study included time spent in water-fetching, any water-fetching, and having an improved water source. "Water-fetching" in our study means spending some time outside the household premises to go get water and return to the household. Round-trip time spent by mothers fetching water was categorized into two levels as: round-trip time greater than 30 minutes and round-trip of 30 minutes or less as the referent category; 30 minutes was chosen as the cutoff time to align with the basic drinking water definition used by the World Health Organization (WHO)/ United Nations Children's Fund (UNICEF) Joint Monitoring Programme for Water Supply, Sanitation and Hygiene (JMP) [29]. We also compared any water-fetching, to mothers who did not water-fetch (ie, either the water was close and did not require fetching or someone else in the household fetched the water). We used the definition of improved water, as defined by the JMP, where improved sources include piped water, boreholes or tube wells, protected dug wells, protected springs, tanker-truck, rain water and packaged water, whereas unimproved water sources include unprotected dug wells, springs, and surface water collected directly from river, dam, lake, pond, stream, canal and irrigation channels [29].

\section{Covariates}

Covariates of interest in our data included: educational level of mothers, age of the mother, household wealth, sanitation and residential status. Mother's educational level was categorized as no education, primary, secondary and college or higher education. Household wealth was expressed in wealth quintiles as a composite indicator of wealth derived from principal component analysis using household assets [26]. We categorized wealth quintiles as upper two, middle and lower two wealth quintiles. Sanitation was also categorized as improved vs unimproved sanitation according JMP's definition of basic sanitation [30]. Residential status was recorded as either urban or rural.

\section{Data analysis}

Characteristics of study participants across 19 African countries were presented as counts and percentages (if categorical) and as mean and standard deviation (if continuous). Multivariable logistic regression was used to assess the relationships between the variables of interest and outcome variables, while controlling for potential confounders. In estimating the relationship between access to improved water sources, and outcomes (EBF and diarrhea), and between household water-fetching and EBF, we controlled for educational level of the mothers, household wealth, sanitation and residential status. When assessing the relationship between EBF and diarrhea prevalence in children five months old or less, we adjusted for the educational level of the mothers, household wealth, sanitation, maternal age, child's age and residential status. We specified all our potential confounders a priori, as we thought there was biological plausibility that they might be associated with both the exposure and outcome of interest. We used survey procedures in SAS to account for the stratified design (ie, strata, clusters, and sampling weights) for all analyses.

We conducted a sensitivity analysis on the association between round-trip time spent by mothers fetching water and EBF to see whether there was a dose response relationship with increasing time spent. We compared EBF prevalence among mothers who spent a round-trip of between 30 minutes and 60 minutes, and a round trip of greater than 60 minutes, to mothers who spent a round-trip of 30 minutes or less as the referent category [29].

We also tested whether child (age categories 0-1, 2-3 and 4-5 months of age) [4], moderates the role of time spent by mothers fetching water on EBF. As a secondary descriptive analysis, we also show the prevalence of EBF among mothers with children of different age categories (0-1, 2-3, 4-5 \& $\leq 5$ months), and the mean time spent by mothers during water-fetching. Data were analyzed using SAS version 9.3 (SAS Institute, Cary, NC) for descriptive statistics and multivariable logistic regression.

\section{Synthesis of Results across all countries}

Random-effects meta-analysis with inverse variance weighting was used to pool adjusted odds ratios estimates of our key relationships across all 19 countries. We reported statistical heterogeneity using the $\mathrm{I}^{2}$ statistics. An $\mathrm{I}^{2}>50 \%$ may be of substantial heterogeneity, while that of an $\mathrm{I}^{2}>75 \%$ may be of considerable heterogeneity [31]. We present results both by each country and overall using forest plots. The meta-analysis was conducted using Stata 16 SE (Stata Corp, College Station, TX, USA). 


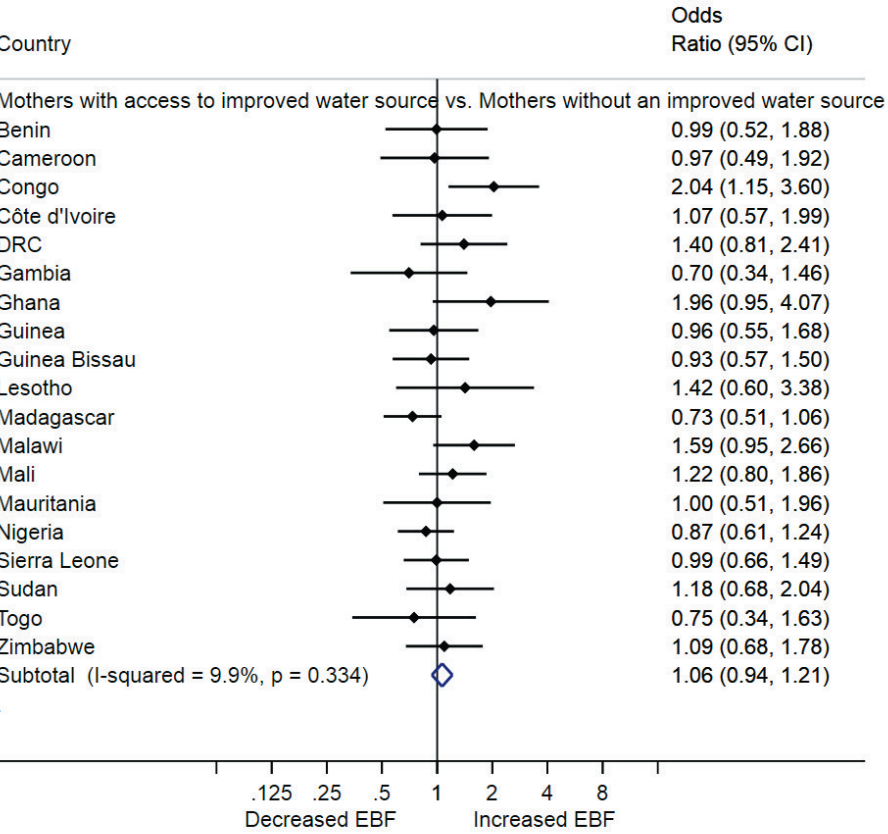

Figure 1. The association between access to an improved water source and exclusive breastfeeding (EBF) practice among mothers in 19 African countries.

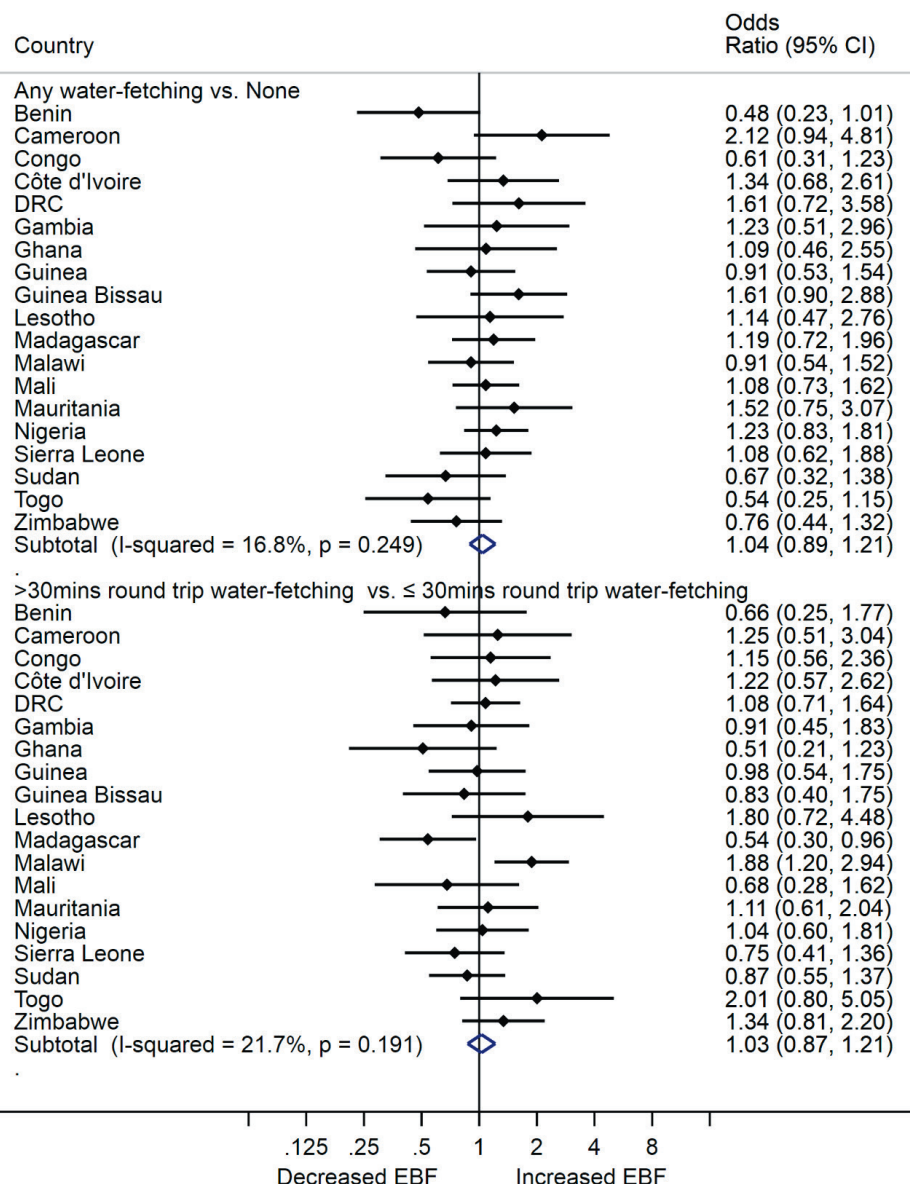

Figure 2. The association between any water-fetching and times spent by mothers fetching water and exclusive breastfeeding (EBF) practice among mothers in 19 African countries.
RESULTS

\section{Descriptive statistics}

The MICS data from the 19 countries was restricted to a total 247090 mothers with children 5 months old or less living in a mix of rural and urban areas (Table 1). The mean age of mothers across the countries ranged from 25-29 years. Twelve of the countries (Gambia, Ghana, Lesotho, Sierra Leone, Togo, Côte d'Ivoire, Guinea Bissau, Guinea, Malawi, Mauritania, Nigeria, and Sudan) had majority of mothers with no formal education (Table 1). The prevalence of EBF ranged from $22 \%$ in Nigeria to $70 \%$ in Malawi and EBF prevalence was at least $50 \%$ in 9 of the 19 countries (Table 1). Not surprisingly, the prevalence of EBF decreased with increasing age of the child across all countries (Figure S1 in the Online Supplementary Document). The prevalence of any breastfeeding (ie, currently breastfeeding, without regard to supplemental food or water) among mothers with children 5 months old or less ranged from 97\% to $100 \%$ across countries (Table 1). The mean time spent by mothers fetching water ranged from 20 minutes in Ghana to 115 minutes in Mauritania (Table 1).

\section{Factors associated with prevalence of EBF and prevalence of diarrhea}

The overall prevalence of EBF was similar between mothers with access to an improved water source and mothers without such access (adjusted prevalence odds ratios (aPOR):1.06, 95\% CI=0.94, 1.21), and there was little heterogeneity in the estimates across the 19 countries $\left(\mathrm{I}^{2}=9.9 \%, P=0.334\right)$. Most individual countries had null results when assessing the association between access to an improved water source and EBF, although mothers in Congo with access to an improved water source were twice as likely to exclusively breastfeed as compared to their peers with an unimproved water source $(\mathrm{aPOR}=2.04,95 \% \mathrm{CI}=1.15,3.60$; Figure 1$)$.

There was no relationship between water-fetching and EBF, regardless of how water fetching was categorized (Figure 2). The prevalence of EBF was similar comparing mothers who participated in any water-fetching to mothers who did not fetch water at all (aPOR $=1.04,95 \% \mathrm{CI}=0.89,1.21)$. All 19 countries had null findings, with low heterogeneity across estimates $\left(I^{2}=16.8 \%, P=0.249\right)$. Similarly, the prevalence of EBF was comparable between mothers who spent greater than 30 minutes round-trip water-fetching and mothers who spent $\leq 30$ minutes round-trip water-fetching $(\mathrm{aPOR}=1.03,95 \% \mathrm{CI}=0.87,1.21)$, again with little heterogeneity in the estimates $\left(\mathrm{I}^{2}=21.7 \%, P=0.191\right.$; Figure 2). In Madagascar, mothers who spent greater than 30 minutes water-fetching had $46 \%$ lower odds of EBF compared to mothers who spent 30 minutes or less (aPOR $=0.54,95 \% \mathrm{CI}=0.30,0.96)$. In contrast, mothers in Malawi who spent greater than 30 minutes wa- 


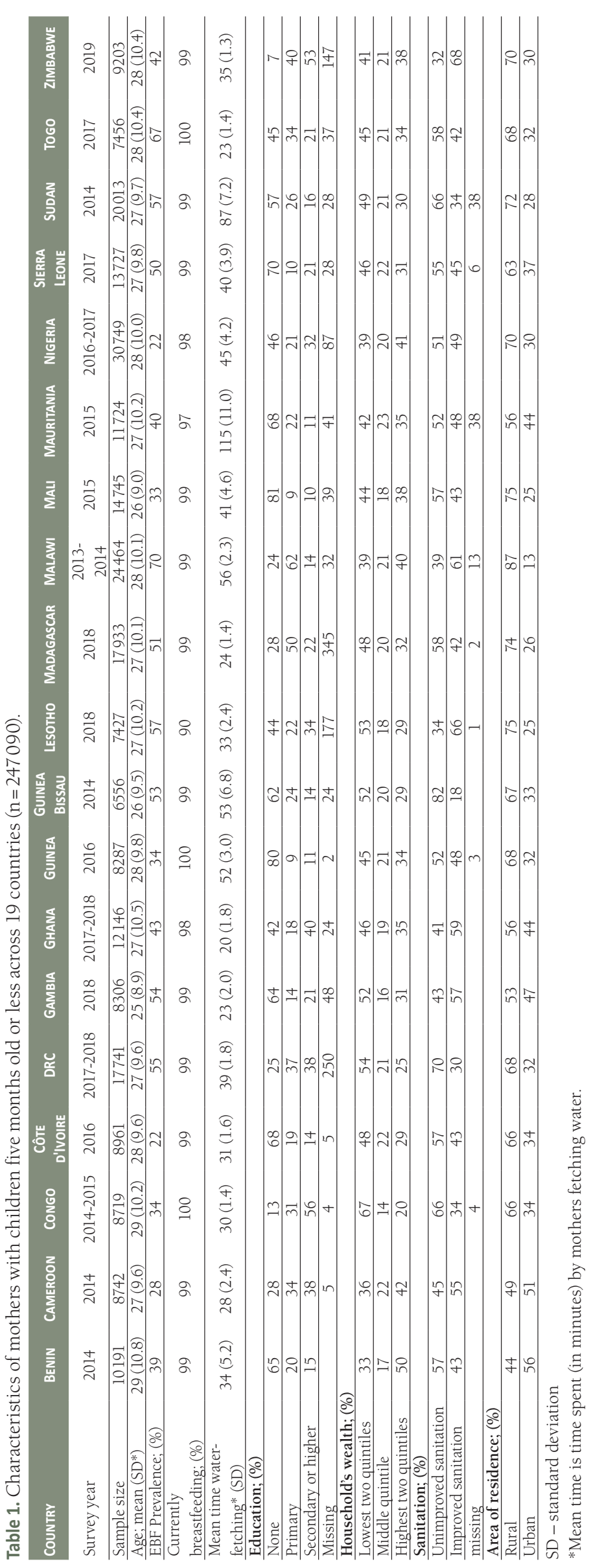

ter-fetching had 88\% higher odds of EBF compared to mothers who spent 30 minutes or less. Our sensitivity analysis to assess if there was a dose response between water-fetching time and EBF showed that prevalence of EBF was similar between various times spent water-fetching (Figure S2 in the Online Supplementary Document). Also, our sensitivity analysis to assess whether child age moderates the relationship between time spent by mothers fetching water and EBF showed similar prevalence of EBF among child age ranges 0-1, 2-3 and 4-5 months (Figure S3 in the Online Supplementary Document).

Overall, children who were exclusively breastfed had $33 \%$ lower odds of diarrhea than those not breastfed ( $\mathrm{aPOR}=0.67,95 \% \mathrm{CI}=0.56,0.78$ ), and this finding was consistent across many of the countries $\left(\mathrm{I}^{2}=0.00 \%\right.$, $P=0.592$; Figure 3). The prevalence of diarrhea in children five months old or less was similar between mothers with access to an improved water source and mothers without access to an improved water source $\left(\mathrm{aPOR}=0.94,95 \% \mathrm{CI}=0.76,1.15 ; \mathrm{I}^{2}=23.7 \%, P=0.169\right.$; Figure 3).

\section{DISCUSSION}

The study assessed 247090 mothers with children 5 months old or less from 19 countries in Africa, and offers new insight into whether water access and household water-fetching play a role in a mothers' practice of EBF. Existing literature shows water-fetching leads to a significant burden on women in a number of areas [32], however, we did not observe water access or water-fetching to be associated with mothers' practice of exclusive breastfeeding. The literature also describes the importance of breastfeeding on health [33] and our study is consistent in finding lower prevalence of diarrhea with those who practiced EBF. Across the 19 countries, time spent fetching water by mothers was often high, and the prevalence of EBF practice among mothers was often low.

We observed that only 9 out of the 19 countries met the WHO's Global Nutrition Target of 50\% EBF prevalence by 2025 [34]. The low prevalence of EBF in some of the countries in our study may be due to socio-cultural beliefs and misinformation about EBF. Barriers to EBF vary across communities, and stem from a variety of factors, including beliefs about breast milk being insufficient, beliefs about water quenching thirst, traditions of giving water as a welcoming, and other taboos and social norms [35-38]. Countries with low EBF prevalence in our study could benefit from increased promotion of EBF, education and support [39].

Our study also found that many mothers spent a significant amount of time water-fetching. Mothers on average spent more than 30 minutes round-trip water-fetching in 13 of the 19 countries. Spending more than 30 


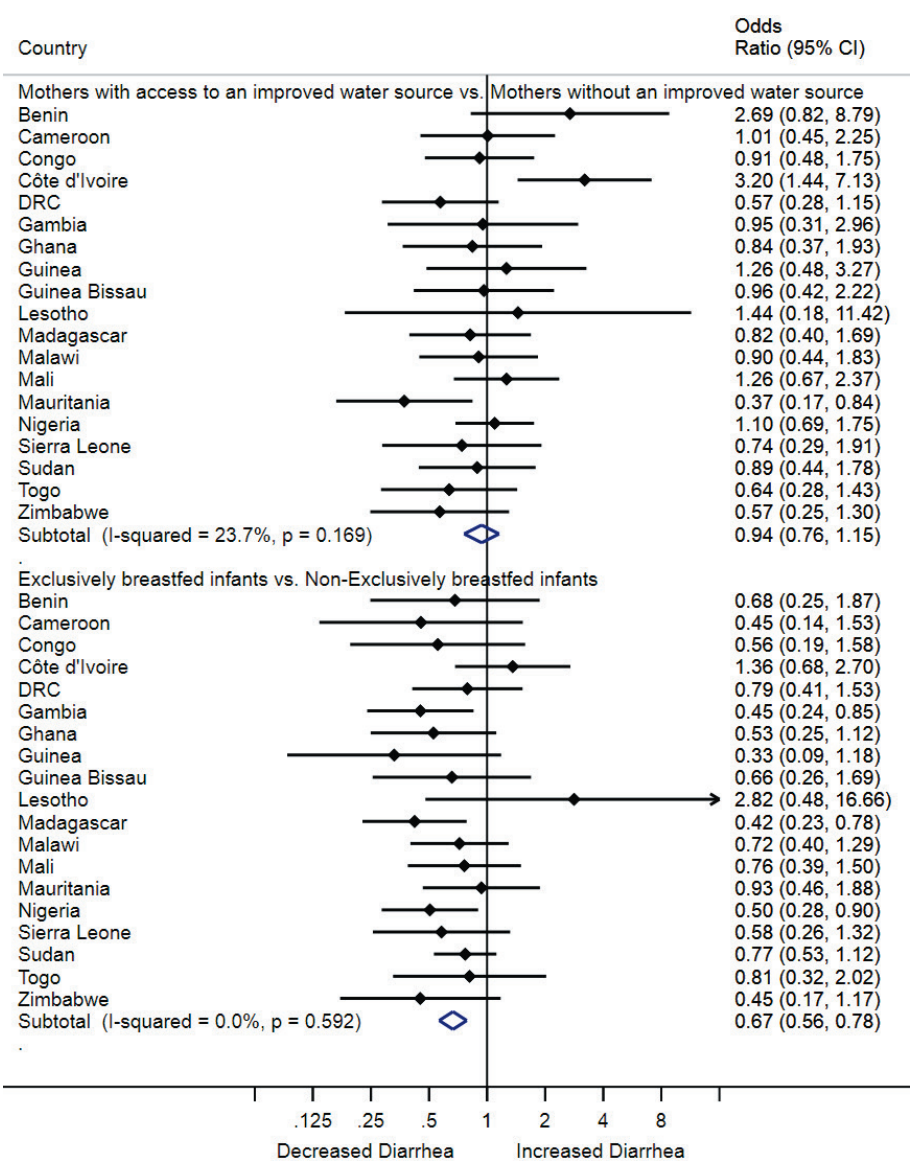

Figure 3. The association between access to improved water sources, exclusive breastfeeding practice, and diarrhea prevalence in children five months old or less in 19 African countries. minutes would categorize these women as not having "basic drinking water" as defined by JMP [29]. Previous studies have also reported a round-trip time greater than 30 minutes among women that water-fetch, though their finding was not limited to only mothers $[8,40]$. Studies have also suggested that the total time spent in water-fetching might be higher depending on the number of trips required per day and persons involved in household water-fetching [40,41].

The WHO recommends having accessible, on premise water, in part to reduce water collection time [30]. Our results do not change these policy recommendations. We found a high prevalence of water-fetching in the countries under study. Even though our research did not find an association between water-fetching and EBF, other research has reported on the numerous detriments of water fetching. Water fetching has been found to lead to psychological and emotional distress as well as musculoskeletal injury/pain [41,42]. A reduction in time spent water-fetching has also been found to be associated with reduced diarrhea prevalence, improved anthropometric indicators of child nutritional status, and a reduction in under-five mortality [11]. Women have traditionally carried much of the burden of water-fetching, [9] and this was evident in our study where in each of the 19 countries, women spent more than 20 minutes on average water-fetching, and in the most extreme country up to 115 minutes fetching water.

Our findings of no difference in EBF prevalence between mothers who fetched water and those who did not fetch water may be due to several reasons. Many mothers may value and prioritize EBF regardless of the time constraints imposed by water-fetching. Mothers in Africa often carry infants on their back during water-fetching [43], and may exclusively breastfeed their child on their trip when the child is hungry regardless of timing. It's also possible that children are exclusively breastfed, but just not as frequently or for the same duration during times when mothers are fetching water.

While we hypothesized that mothers who perceived their water source as being clean might supplement their child's feedings with water at an earlier age, we found that access to an improved water source was not associated with a mother's practice of EBF. Our hypothesis was based on previous studies that reported beliefs that infants can be given water if the water is thought to be clean [16]. Our study is limited in that it measured whether the household had an improved water source, which is an imperfect indicator for whether the household had a microbiologically safe water source [20], but did not measure mothers' perceptions of the water cleanliness.

Our study findings assessing the relationship between water, EBF and diarrhea align well with published literature. We found that EBF was associated with reduced prevalence of diarrhea in children, and this observation is consistent with previous studies on EBF and diarrhea [44-46]. We also found that access to an improved water source was not associated with diarrhea prevalence. Recent systematic reviews and rigorous trials assessing the effects of water interventions on diarrhea have been mixed [47-49].

Our study had several strengths and limitations. Strengths include that our study draws from many countries from Africa, and therefore our findings should be generalizable to the countries in our study and potentially the regions beyond our study countries. The data collection in this study was also designed to be standardized, rigorous and internationally comparable. A major limitation is that the findings cannot be interpreted causally, as this was a cross-sectional study. Another limitation is that EBF status was assessed at a single point in time using the 24-hour recall, which is known to overestimate the true prevalence of EBF practice because some infants who are given other liquids/foods irregularly may not have received them on a daily basis before the survey [50]. Although this might be a limitation in our study, the estimation of EBF status in our study is standard practice, and is consistent with international guidelines [28]. The outcomes of interest 
were self-reported, and thus may be subject to recall bias. However, we have no reason to expect recall to be different between mothers who water-fetched vs those who did not. Another limitation was that we could not control for some potential confounders such as previous history of EBF, knowledge on the benefits of EBF, household water sharing and seasonality (ie, wet or dry season), as these variables are not available in the MICS data. We also were unable to control for the complexity of which persons were involved in household water-fetching, for example, how many people/which persons were involved in household water-fetching. More than one person is usually involved in household water-fetching in Africa [8,40].

\section{CONCLUSION}

This is the first study to evaluate the role of water access and household water-fetching on exclusive breastfeeding practice by mothers. We found that access to an improved water source and time spent by mothers fetching water were not associated with a mother's practice of EBF. The study draws on data from 19 countries throughout Africa, and the findings were generally consistent across countries. At a policy level, our findings lend support to the importance of Sustainable Development Goal (SDG) target 6.1, which promotes universal access to drinking water, and the WHO call to increase the prevalence of EBF globally [34,51]. While our study was cross-sectional, future research using more rigorous designs may still be merited to understand if similar results would persist. Future research with a qualitative approach may be needed to elucidate why water access was not associated with EBF. Studies might also examine whether time spent water-fetching is associated with frequency of breastfeeding.

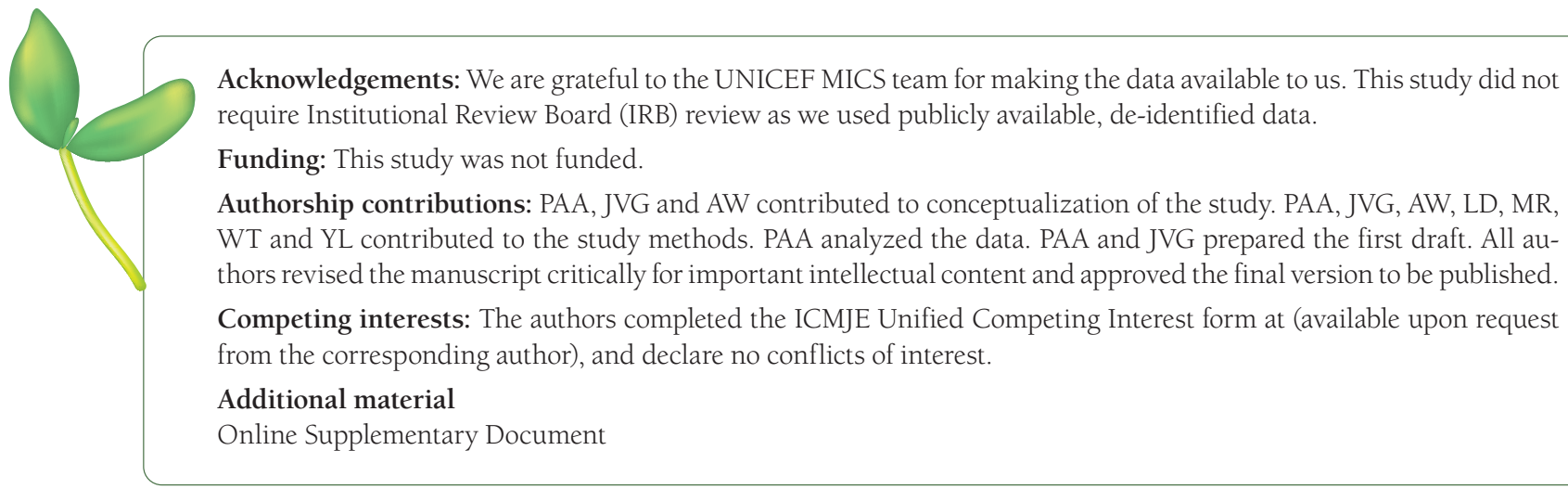

1 Walker CL, Rudan I, Liu L, Nair H, Theodoratou E, Bhutta ZA, et al. Global burden of childhood pneumonia and diarrhoea. Lancet. 2013;381:1405-16. Medline:23582727 doi:10.1016/S0140-6736(13)60222-6

2 Liu L, Johnson HL, Cousens S, Perin J, Scott S, Lawn JE, et al. Global, regional, and national causes of child mortality: an updated systematic analysis for 2010 with time trends since 2000. Lancet. 2012;379:2151-61. Medline:22579125 doi:10.1016/ S0140-6736(12)60560-1

3 WHO. Water,sanitation and hygiene interventions and the prevention of diarrhoea. 2011. Available: https://www.who.int/ elena/titles/bbc/wsh_diarrhoea/en/. Accessed: 6 December 2018.

4 WHO. Indicators for assessing infant and young child feeding practices. 2008. Available: http://whqlibdoc.who.int/publications/2008/9789241596664_eng.pdf. Accessed: 18 September 2018.

5 Patel A, Bucher S, Pusdekar Y, Esamai F, Krebs NF, Goudar SS, et al. Rates and determinants of early initiation of breastfeeding and exclusive breast feeding at 42 days postnatal in six low and middle-income countries: A prospective cohort study. Reprod Health. 2015;12 Suppl 2:S10. Medline:26063291 doi:10.1186/1742-4755-12-S2-S10

6 Westerfield KL, Koenig K, Oh R. Breastfeeding: Common Questions and Answers. Am Fam Physician. 2018;98:368-73. Medline:30215910

7 UNICEF. Progress for children: A report card on nutrition. 2006. Available: https://data.unicef.org/resources/progress-forchildren-a-report-card-on-nutrition/. Accessed: 2 January 2019.

8 Graham JP, Hirai M, Kim SS. An Analysis of Water Collection Labor among Women and Children in 24 Sub-Saharan African Countries. PLoS One. 2016;11:e0155981. Medline:27248494 doi:10.1371/journal.pone.0155981

9 Geere J-A, Cortobius M. Who Carries the Weight of Water? Fetching Water in Rural and Urban Areas and the Implications for Water Security Water Alternatives. 2017;10:513-40.

10 Geere JL, Hunter PR. The association of water carriage, water supply and sanitation usage with maternal and child health. A combined analysis of 49 Multiple Indicator Cluster Surveys from 41 countries. Int J Hyg Environ Health. 2020;223:23847. Medline:31488359 doi:10.1016/j.ijheh.2019.08.007 
11 Pickering AJ, Davis J. Freshwater availability and water fetching distance affect child health in sub-Saharan Africa. Environ Sci Technol. 2012:46:2391-7. Medline:22242546 doi:10.1021/es203177v

12 Nygren BL, O'Reilly CE, Rajasingham A, Omore R, Ombok M, Awuor AO, et al. The Relationship Between Distance to Water Source and Moderate-to-Severe Diarrhea in the Global Enterics Multi-Center Study in Kenya, 2008-2011. Am J Trop Med Hyg. 2016;94:1143-9. Medline:26928833 doi:10.4269/ajtmh.15-0393

13 Wright J, Gundry S, Conroy R. Household drinking water in developing countries: a systematic review of microbiological contamination between source and point-of-use. Trop Med Int Health. 2004;9:106-17. Medline:14728614 doi:10.1046/ j.1365-3156.2003.01160.x

14 Rufener S, Mäusezahl D, Mosler HJ, Weingartner R. Quality of drinking-water at source and point-of-consumption-drinking cup as a high potential recontamination risk: a field study in Bolivia. J Health Popul Nutr. 2010;28:34-41. Medline:20214084 doi:10.3329/jhpn.v28i1.4521

15 Mattioli MC, Boehm AB, Davis J, Harris AR, Mrisho M, Pickering AJ. Enteric pathogens in stored drinking water and on caregiver's hands in Tanzanian households with and without reported cases of child diarrhea. PLoS One. 2014;9:e84939. Medline:24392161 doi:10.1371/journal.pone.0084939

16 Otoo GE, Lartey AA, Pérez-Escamilla R. Perceived incentives and barriers to exclusive breastfeeding among periurban Ghanaian women. J Hum Lact. 2009;25:34-41. Medline:18971507 doi:10.1177/0890334408325072

17 Anthonj C, Fleming L, Godfrey S, Ambelu A, Bevan J, Cronk R, et al. Health Risk Perceptions Are Associated with Domestic Use of Basic Water and Sanitation Services-Evidence from Rural Ethiopia. Int J Environ Res Public Health. 2018;15:2112. Medline:30261590 doi:10.3390/ijerph15102112

18 Gwimbi P, George M, Ramphalile M. Bacterial contamination of drinking water sources in rural villages of Mohale Basin, Lesotho: exposures through neighbourhood sanitation and hygiene practices. Environ Health Prev Med. 2019;24:33. Medline:31092211 doi:10.1186/s12199-019-0790-z

19 Bain R, Cronk R, Wright J, Yang H, Slaymaker T, Bartram J. Fecal contamination of drinking-water in low- and middle-income countries: a systematic review and meta-analysis. PLoS Med. 2014;11:e1001644. Medline:24800926 doi:10.1371/journal.pmed.1001644

20 Bain RE, Gundry SW, Wright JA, Yang H, Pedley S, Bartram JK. Accounting for water quality in monitoring access to safe drinking-water as part of the Millennium Development Goals: lessons from five countries. Bull World Health Organ. 2012;90:228-235A. Medline:22461718 doi:10.2471/BLT.11.094284

21 UNICEF. Progress for Children: A report card on water and sanitation (No. 5). 2006. Available: https://www.unicef.org/publications/index_35977.html. Accessed: 23 July 2020.

22 Black RE, Morris SS, Bryce J. Where and why are 10 million children dying every year? Lancet. 2003;361:2226-34. Medline:12842379 doi:10.1016/S0140-6736(03)13779-8

23 Boschi-Pinto C, Velebit L, Shibuya K. Estimating child mortality due to diarrhoea in developing countries. Bull World Health Organ. 2008;86:710-7. Medline:18797647 doi:10.2471/BLT.07.050054

24 Dreibelbis R, Freeman MC, Greene LE, Saboori S, Rheingans R. The impact of school water, sanitation, and hygiene interventions on the health of younger siblings of pupils: a cluster-randomized trial in Kenya. Am J Public Health. 2014;104:e917. Medline:24228683 doi:10.2105/AJPH.2013.301412

25 Khan S, Hancioglu A. Multiple Indicator Cluster Surveys: Delivering Robust Data on Children and Women across the Globe. Stud Fam Plann. 2019;50:279-86. Medline:31486080 doi:10.1111/sifp.12103

26 UNICEF. Multiple Indicator Cluster Survey (MICS). 2019. Available: https://mics.unicef.org/. Accessed: 23 December 2019.

27 National Bureau of Statistics and UNICEF. Multiple indicator cluster survey 2016-2017, survey findings report. Abuja, Nigeria: National Bureau of Statistics and United Nations Children's Fund: 2017.

28 Pullum TW. Exclusive breastfeeding: aligning the indicator with the goal. Glob Health Sci Pract. 2014;2:355-6. Medline:25276594 doi:10.9745/GHSP-D-14-00061

29 WHO. UNICEF. Safely managed drinking water - thematic report on drinking water 2017. 2017. Available: https://data.unicef. org/wp-content/uploads/2017/03/safely-managed-drinking-water-JMP-2017-1.pdf. Accessed: 11 December 2019.

30 UNICEF. WHO. Progress on Drinking Water,Sanitation and Hygiene: 2017 Update and SDG Baselines. 2017. Available: https://apps.who.int/iris/bitstream/handle/10665/258617/9789241512893-eng.pdf?sequence=1. Accessed: 16 October 2018.

31 Higgins J, Green S. Collaboration. Cochrane Handbook for Systematic Reviews of Interventions. 2008. Available: https:// handbook-5-1.cochrane.org/. Accessed: 16 October 2018.

32 Geere J-A, Cortobius M. Who Carries the Weight of Water? Fetching Water in Rural and Urban Areas and the Implications for Water Security. Water Altern. 2017;10:513-40.

33 Sankar MJ, Sinha B, Chowdhury R, Bhandari N, Taneja S, Martines J, et al. Optimal breastfeeding practices and infant and child mortality: a systematic review and meta-analysis. Acta Paediatr. 2015;104:3-13. Medline:26249674 doi:10.1111/ apa.13147

34 WHO. UNICEF. Global Nutrition Targets 2025: Breastfeeding Policy Brief (WHO/NMH/NHD/14.7). Geneva: World Health Organization: 2014.

35 Balogun OO, Dagvadorj A, Anigo KM, Ota E, Sasaki S. Factors influencing breastfeeding exclusivity during the first 6 months of life in developing countries: a quantitative and qualitative systematic review. Matern Child Nutr. 2015;11:433-51. Medline:25857205 doi:10.1111/mcn.12180

36 Kavle JA, LaCroix E, Dau H, Engmann C. Addressing barriers to exclusive breast-feeding in low- and middle-income countries: a systematic review and programmatic implications. Public Health Nutr. 2017;20:3120-34. Medline:28965508 doi:10.1017/S1368980017002531

37 Talbert A, Jones C, Mataza C, Berkley JA, Mwangome M. Exclusive breastfeeding in first-time mothers in rural Kenya: a longi- 
tudinal observational study of feeding patterns in the first six months of life. Int Breastfeed J. 2020;15:17. Medline:32138727 doi:10.1186/s13006-020-00260-5

38 Paula D, Darko T, Mukuria A. Water, Koko, and Appetite: Complementary Feeding Practices in Kumasi, Ghana. Calverton, Maryland USA: ORC Macro: 2003.

39 Bhattacharjee NV, Schaeffer LE, Marczak LB, Ross JM, Swartz SJ, Albright J, et al. Mapping exclusive breastfeeding in Africa between 2000 and 2017. Nat Med. 2019;25:1205-12. Medline:31332393 doi:10.1038/s41591-019-0525-0

40 Sorenson SB, Morssink C, Campos PA. Safe access to safe water in low income countries: water fetching in current times. Soc Sci Med. 2011;72:1522-6. Medline:21481508 doi:10.1016/j.socscimed.2011.03.010

41 Geere JA, Hunter PR, Jagals P. Domestic water carrying and its implications for health: a review and mixed methods pilot study in Limpopo Province, South Africa. Environ Health. 2010;9:52. Medline:20796292 doi:10.1186/1476-069X-9-52

42 Stevenson EG, Greene LE, Maes KC, Ambelu A, Tesfaye YA, Rheingans R, et al. Water insecurity in 3 dimensions: an anthropological perspective on water and women's psychosocial distress in Ethiopia. Soc Sci Med. 2012;75:392-400. Medline:22575697 doi:10.1016/j.socscimed.2012.03.022

43 World Vision. Carrying water can be a pain in the neck. 2017. Available: https://www.worldvision.org/clean-water-newsstories/carrying-water-pain-neck. Accessed: 17 May 2020.

44 Kramer MS, Kakuma R. Optimal duration of exclusive breastfeeding. Cochrane Database Syst Rev. 2012;CD003517. Medline:22895934

45 Arifeen S, Black RE, Antelman G, Baqui A, Caulfield L, Becker S. Exclusive breastfeeding reduces acute respiratory infection and diarrhea deaths among infants in Dhaka slums. Pediatrics. 2001;108:E67. Medline:11581475 doi:10.1542/peds.108.4.e67

46 Horta B, Victora C. WHO. Short-term effects of breastfeeding: a systematic review on the benefits of breastfeeding on diarrhoea and pneumonia mortality. 2013. Available: https://apps.who.int/iris/handle/10665/95585. Accessed: 27 November 2019.

47 Clasen TF, Alexander KT, Sinclair D, Boisson S, Peletz R, Chang HH, et al. Interventions to improve water quality for preventing diarrhoea. Cochrane Database Syst Rev. 2015;CD004794. Medline:26488938 doi:10.1002/14651858.CD004794.pub3

48 Stewart CP, Kariger P, Fernald L, Pickering AJ, Arnold CD, Arnold BF, et al. Effects of water quality, sanitation, handwashing, and nutritional interventions on child development in rural Kenya (WASH Benefits Kenya): a cluster-randomised controlled trial. Lancet Child Adolesc Health. 2018;2:269-80. Medline:29616236 doi:10.1016/S2352-4642(18)30025-7

49 Null C, Stewart CP, Pickering AJ, Dentz HN, Arnold BF, Arnold CD, et al. Effects of water quality, sanitation, handwashing, and nutritional interventions on diarrhoea and child growth in rural Kenya: a cluster-randomised controlled trial. Lancet Glob Health. 2018;6:e316-29. Medline:29396219 doi:10.1016/S2214-109X(18)30005-6

50 Aarts C, Kylberg E, Hörnell A, Hofvander Y, Gebre-Medhin M, Greiner T. How exclusive is exclusive breastfeeding? A comparison of data since birth with current status data. Int J Epidemiol. 2000;29:1041-6. Medline:11101545 doi:10.1093/ ije/29.6.1041

51 UN. Sustainable Development Goals: About the Sustainable Development Goals. 2016. Available: https://www.un.org/sustainabledevelopment/sustainable-development-goals/. Accessed: 16 November 2020. 